Flipping Engineering Probability and Statistics - Lessons Learned for Faculty Considering the Switch

Dr. Rick Olson, University of San Diego 


\title{
Flipping Engineering Probability and Statistics - Lessons Learned for Faculty Considering the Switch
}

\begin{abstract}
During the Spring 2013 semester, the Sophomore level probability and statistics class ISYE 330 at the University of San Diego was taught using the Flipped Classroom strategy. Most lectures were delivered in short online videos. Each class began with a brief review lecture and students spent most of the remaining class time solving problems in groups. Compared to the Spring 2012 offering, the same material was covered in less time and test scores on a common final exam increased.

This paper summarizes the lessons-learned by teaching ISYE 330 as a flipped class. Class organization is contrasted with earlier versions of the course. The preparation of online and supplementary materials is described including a discussion of the evolution of the materials as the semester progressed. Student performance is analyzed and compared to previous offerings. Course evaluations are examined to gain insight into student attitudes to flipped classes. Finally, the advantages and disadvantages of using the flipped strategy are summarized along with suggestions for how class could be changed in the future to make even more effective use of class time and enhance student learning.
\end{abstract}

\section{Background}

At the University of San Diego (USD), all engineers are required to take either ISYE 330 Engineering Probability \& Statistics or another course in probability and statistics in the Mathematics Department. The majority of the students take ISYE 330. ISYE 330 is a standard introductory statistics class based on the text Applied Statistics and Probability for Engineers ${ }^{1}$. The class is designed to introduce probability distributions, descriptive statistics, confidence intervals and hypothesis tests to engineers of all majors, while laying the foundation for courses in statistical process control and design of experiments that are required of industrial and systems engineering (ISyE) majors. Prior to Spring 2012, students were expected to take the class their $5^{\text {th }}$ semester and the class was offered only in the fall. Since Spring 2012, the class has been offered every semester. Students are expected to take it during the second semester of their sophomore year, but some non-ISyE majors delay the class until their junior or senior year, or take the class offered in the math department. The class meets three times per week, 55 minutes per class. Enrollment is limited to 40 people per section. The author taught all sections of ISYE 330 from Fall 2010 through Spring 2013. During the Fall 2012 semester, part of the course was taught using a flipped, or inverted, teaching model. In Spring 2013, the entire course was taught in this way.

In a traditional class setting, content delivery takes place in the classroom (most typically through lectures) and students solve homework and do other learning activities outside of class. In the flipped classroom, those activities are reversed. Content delivery occurs outside of class, most often through video lectures, or readings, and class time is used for active learning activities such as simple problem solving, case analysis, or problem-based learning activities that are conducted in the presence of the instructor who can intervene where needed to clarify 
concepts, resolve problems, or pose new questions. Flipped classrooms have been used in a wide range of courses at all educational levels. A survey of the research on flipped classrooms has been reported by Bishop and Vergler $^{2}$ and includes examples related to industrial engineering ${ }^{3,4}$.

\section{Previous offerings of ISYE 330}

\subsection{Fall 2010 - Spring 2012 offerings}

In Fall 2010, the author taught ISYE 330 for the first time in over a decade. Because the book had changed and the focus of the class had changed, he treated the class as a new preparation and developed new lectures. Keeping with how he teaches most classes, most lecture content was delivered through PowerPoint. The course was composed of approximately 20 handouts. Each handout covered a different topic, and took one or two in-class lectures to complete. A whiteboard was used to supplement the material on the PowerPoint slides, particularly when answering student questions, or when some equations or figures would be referred to throughout the lecture. The class was also taught using active learning techniques. For example, throughout the lectures questions were posed to seed Think-Pair-Share activities. The handouts of the PowerPoint were given to the students, but there were many blanks in the slides. Some of the information was completed by the instructor using the pen-enabled monitor in the classroom, but many blank spaces were problems that were completed by students individually, or in small teams. A typical class period would include 1-3 short problems to be solved. Homework assignments for each handout were completed in teams ${ }^{5}$.

About 3 weeks into the semester, the instructor asked students what changes could be made that would make the course effective. Students overwhelmingly commented that they wanted more examples worked in class. They also noted that the problems solved in class didn't look like the homework problems, so some students were having difficulties starting the homework. This made homework teams less effective since students were expected to meet with their teams having read the problems and outlined a solution approach. Some students were able to make the transition from lecture problems to text problems easily, but others had more difficulty and came to team meetings unprepared.

It was unrealistic to add more examples to the lectures. Instead, a series of demonstration videos were created in the style of the lessons offered by the Khan Academy ${ }^{6}$. These videos showed the instructor talking through the solution to unassigned problems from the text. By including the text of each problem on the screen, he could show which phrases in a problem statement directed his work. (Details on how the videos were created are described in the appendix.) The intent was that students who wanted to see more examples could watch the videos before attempting the homework or meeting with their homework team. In addition, a special series of four videos was developed around Bayes’ Theorem. These videos reviewed the theory, and then worked through 4 increasingly difficult problems. The response to these videos was immediate, and universally positive. Because of the student feedback, videos were been created for approximately 60 problems by the end of the semester.

ISYE 330 was not offered in the Spring 2011 semester. In Fall 2011 some lecture were improved and more video solutions to textbook problems were recorded. In Spring 2012, there 
were 39 students in one section of ISYE 330. The 24 handouts in the class were delivered in the same manner as Fall 2010 and 2011 there were video solutions to 81 textbook problems. This section of students is the most similar to the ones who experienced the flipped offering in Spring 2013, and student performance in Spring 2012 and 2013 will be compared.

\subsection{Fall 2012 offering}

During the Fall 2012 semester, 18 students were enrolled in ISYE 330. As is common for the Fall offering at our school, this class was more diverse than a spring offering. There were 6 sophomores, 8 juniors, and 4 seniors including 1 student in the 9th semester of study. Several of the students were transfer students. The result was a group of students who learned at very different rates. In particular, there were 3 students who asked many more questions than usual. Because of one student's learning disability, the instructor felt it was important to try to resolve those problems during the lecture so subsequent ideas would be understood. Overall, the class was slowed down and some topics were not covered as thoroughly in lecture as desired. It also caused some problems as students who understood the material became restless during the frequent explanations.

After the second midterm exam, the instructor decided to try flipping the classroom for the remainder of the semester. This decision was based on four considerations:

- By assigning students to watch videos before class and devoting class time to solving problems, the class would stay on track.

- The instructor was facing two 40-person sections in the Spring 2013 semester. If flipping proved effective, then using it in the spring would be a simple way to ensure that both sections would remain in sync throughout the semester.

- Flipping the class might provide a way to manage the few students with an unusual number of questions. Those questions could be addressed one-on-one or in small groups rather than as an entire class.

- One of the people teaching statics to sophomores was using a flipped strategy in his class in Fall 2012. That implementation consisted of taped "chalk and talk" lectures that were distributed online. Several of the sophomores in XZY-123 said that the statics class was working well, and that they liked being able to ask questions when solving problems.

Lecture videos of the handouts for the remainder of the class were prepared as described in the appendix. Students were expected to watch videos before coming to class. There were no other required out-of-class activities. There were no pre-class quizzes, and the problems that had been performed as homework became the in-class exercises. Homework teams only needed to meet outside of class if they were unable to finish an assignment during class time.

The results of this trial were mixed. The class was more successful at staying on schedule, and test scores on the third midterm were similar to the first two tests. Some students commented that they appreciated not needing to find a time to meet with their homework team outside of class. On the other hand, students found the lectures very long and unexciting. A lecture that took 55 minutes of class time resulted in a 35 minutes video, but it was a boring video. Several students complained that they did not like changing the course delivery so dramatically late in the semester. They had developed a routine, and watching videos wasn't part of the routine. One very strong student also complained about the in-class exercises. She was in the habit of 
completely solving problems before meeting with her homework team. She liked being able to approach a problem by herself the first time she saw it and was distracted by having to interact with her group while she worked through it. This perspective was countered by a casual comment from the student whith a learning disability after the final exam. This student felt that having the lecture videos helped tremendously because a 1-2 minute segment could be repearted as many times as needed to understand a concept. The difficulties encountered with live lectures weren't that the concepts were too difficult. Rather, the pace was too fast. Moving the lectures online allowed the student to control of the pace of instruction. After considering the advantages and disadvantages of flipping that class, the decision was made to flip ISYE 330 in Spring 2013.

\section{Spring 2013 flipped-class offering of ISYE 330}

In Spring 2013, two sections of ISYE 330 were offered. Both sections began the semester with 40 students. Three dropped the course during the semester. The general structure of the flipped portion of the class was the same is in the last month of Fall 2012:

- Students were assigned one or more lecture videos to watch before coming to class.

- Each class began with a short, 5-15 minute, mini-lecture that reviewed the highlights of the video lecture. This provided an opportunity to clear up any questions students had after watching the videos.

- Students work on sets of 2-3 problems in groups of 3 or 4 students. The instructor circulated around the room answering questions, or giving guidance to teams that were having problems. When common issues were identified among several teams, the instructor would take control of the class for a few minutes to clarify matters.

- Students turned in one solution to the problems for their teams.

There was one minor change from the implementation in Fall 2012. Then, the exercises that students worked on during class were problems from the textbook that had been assigned as homework from Fall 2010 - Spring 2012. In Spring 2013 different problems were used. Sometimes these problems came from other books, sometimes they were written for the class.

Overall, the following material was available for the students online:

- 24 PowerPoint lecture handouts

- 63 video lectures corresponding to the handouts

- 81 video lectures to textbook problems

- pdf solutions to 71 additional textbook problems

- $\quad$ pdf solution to the in-class exercises (posted after they were completed)

- $\quad$ solutions to 11 old exams

Some students were intimidated by the volume of material available online. They needed to be reassured several times that the lectures were the only things that they were required to view. The textbook problems and additional pdf solutions were intended to be used as a resource that they could use as needed. 
The class easily covered the same all of the content that was covered in Spring 2012. There were 42, 55-minute classes during the semester. They were used as follows:

- 27 days planned in-class exercise days with assigned sets of videos and corresponding problem sets

- 6 days of "catch up" days used when the planned exercises could not be completed in the planned time.

- 3 midterm exams

- 3 days used as pre-exam problem-solving sessions

- 2 days used to introduce and wrap-up the class

- 1 missed day because of instructor illness

The catch up days generally occurred because there were more student questions than expected at the beginning of class, or because the problems took longer to complete than expected. In general, problem sets were due at the end of class, but if a team hadn't finished, they were often permitted to finish it the next class. When assignments were clearly too long, or too many people were starting a class by finishing up an earlier lesson, the lectures would be suspended for a day and a class would be devoted to finishing backlogged work. On many of these days, the majority of the class finished very early. With a better understanding of the time needed to solve in-class problems, many of these catch up days could have been eliminated and the time could have been used to explore new material or pursue other activities.

The pre-exam days began with a very short summary of what the exam would cover. Then problems from previous tests were distributed throughout the class and each team of students developed solutions to one or two of the problems and wrote the solutions on the board. Many students found these sessions helpful, but they were only possible because the flipped class stayed on track so effectively. In the past, the instructor had never devoted class time to this type of exam review activity. Rather, old tests were made available online for students to review at their discretion.

One thing became evident early in the semester: some teams would finish the exercises quickly, while others would struggle to finish them before the end of class. It was impossible to create problems that would take everyone the same amount of time to complete, so students were allowed to use their free time as they saw fit. Some left class early; others stayed, but did work for different classes. A few helped their friends' groups complete the work. While walking around the class and working with students, four general types of groups emerged:

- Teams who knew how to do essentially everything with little intervention. These people usually only asked questions to clarify a problem statement, or to confirm that their answers were correct.

- Teams who knew the main principles, but who struggled with nuances of some problems. It usually only took a minute or two to resolve their problems.

- Teams who thought they were doing problems correctly, but who were missing important points somewhere in the process.

- Teams who didn’t know where to begin.

The last two groups took the most time, but if they had watched the videos it was usually possible to give them some suggestions, or point to the relevant part of the lecture in two or three 
minutes. Then they were generally able to work on their own for a while before needing more help. If there were 3 or 4 groups (out of 11 or 12 in a class) encountering similar difficulties on a problem, a "time out" was called, and the key principles were elaborated on in a mini-lecture.

The in-class exercises were graded and treated in the same way that homework teams had been handled in the past. To encourage people to work until they got the right answer, teams were told whether their answers were right. Students could only earn credit for assignments completed during class, so regular class attendance was necessary.

\section{Evaluating the effect of the flipped class on student learning}

\subsection{Class Demographics}

Because the Spring 2012 and 2013 offerings of ISYE 330 were taught by the same person, covered the same material and were taken by similar students, they offer an opportunity to compare the impact of the flipped class methodology on student learning. This is done by comparing overall course grades and by student performance on course exams. In particular, identical finals were used each semester and they were graded using the same rubric, so any differences in scores are likely reflect student learning and the different teaching methods.

Table 1 summarizes the students enrolled in ISYE 330 in Spring 2012 and 2013. The most obvious difference is that percentage of women doubled from 2012 to 2013. Also, there were no seniors is 2012. When the students registered for Fall 2011 they did not know that there would be a Spring 2012 offering, so seniors needing the class took it in the fall. The reduction in the percentage of juniors in 2013 reflects the efforts to encourage sophomores to take the class in 2012. Still, the overall percentage of upper-class students is approximately $25 \%$ both years.

Table 1. Demographics of Spring 2012 and 2013 ISYE 330 Classes

\begin{tabular}{|l|c|c|}
\hline & Spring 2012 & Spring 2013 \\
\hline \# of Students & 39 & 77 \\
\hline \# of Men & 33 & 52 \\
\hline \# of Women & 6 & 25 \\
\hline \# of Freshmen & 1 & 2 \\
\hline \# Sophomores & 28 & 56 \\
\hline \# of Juniors & 10 & 10 \\
\hline \# of Seniors & 0 & 9 \\
\hline
\end{tabular}

\subsection{Overall Student Performance}

Table 2 summaries the performance of students on each component of the course. T-Tests for differences between the years are insignificant for all elements other than the homework average. It is difficult to draw meaningful conclusions about the impact of the flipped classroom from these results. Different midterm exams were used each semester. Assuming that the exams were of comparable difficulty, the test performance of the two classes is similar. The final exam will be examined in more detail in section 5, but there was no definitive improvement in scores in the flipped offering. The homework score requires closer examination. 
Table 2. Average Student Performance in

Spring 2012 and 2013 ISYE 330 Classes

\begin{tabular}{|l|c|c|c|c|}
\hline & Spring 2012 & Spring 2013 & t-value & p-value \\
\hline Exam 1 Average & 80.2 & 83.9 & -1.58 & 0.117 \\
\hline Exam 2 Average & 85.4 & 82.3 & 1.36 & 0.177 \\
\hline Exam 3 Average & 88.4 & 86.3 & 1.25 & 0.213 \\
\hline Final Exam Average & 78.8 & 83.2 & -1.78 & 0.078 \\
\hline Homework Average & 99.0 & 89.2 & 5.94 & $3.17 \mathrm{E}-08$ \\
\hline
\end{tabular}

The students did complete the Spring 2012 semester with a much higher average homework score, but the two measures are not directly comparable. In both years a student's score was determined by the formula: HW\% = (Total HW Points)/(.95*Possible Points). Scaling to 95\% of the possible points allowed students to miss an assignment because of illness or absence. In 2013 the Total HW Points score reflects a student's performance on the in-class exercises. In 2012 the Total HW Points included two several extra credit assignments that raised some students score significantly. Anecdotal evidence also suggests that some students probably used solutions found online when preparing their answers. Finally, when homework teams were used in 2012 there was no means of knowing whether all the students on the team actively contributed to the solution. In 2013, students only received credit for work done in class, and the instructor was able to ensure that all students were engaged. Consequently, the high average does not mean that students necessarily knew the material better in Spring 2012.

Figure 1 summarizes the final course grades awarded in Spring 2012 and 2013. At USD, + and grades are awarded, but they have been combined in the figure for clarity. Both semesters yielded a similar percentage of As, but the non-flipped offering in 2012 yielded more Bs while the flipped sections in 2013 resulted in more C’s, D’s, and F's.

There are several explanations for these grade distributions. First, in 2013 in-class work was weighted less heavily than homework assignments in 2012 because 1) it was anticipated that students would be able to receive help while working on in-class assignments and would get high grades, and 2) the exceptionally high homework scores in 2012 were not considered to accurately reflect student effort or learning. Thus, less credit was award for working on problems and more weight was given to exams. This change in grading policy would naturally pull the grades lower. A second factor explaining the lower grades was the lower performance on in-class exercises in 2013 than on homework in 2012. Higher homework scores and higher weights combined to raise course grades. There were some other factors that affected the grades, though.

Three of the nine seniors in 2013 received Cs or Ds in the class. These were all students who put in little effort in the class. Their attention was focused on other classes including their capstone design project. There were also three academic integrity violations during the semester. Those students received Ds or Fs. 


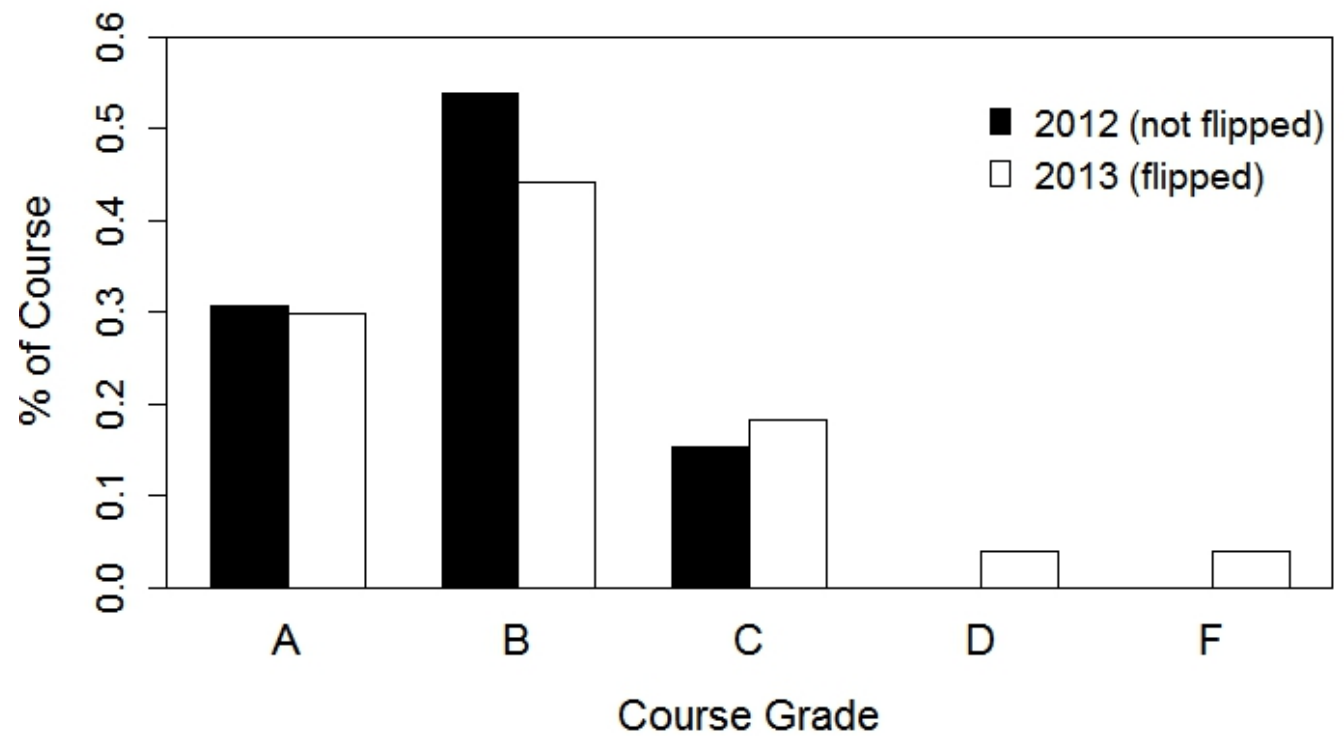

Figure 1. Distribution of course grades in 2012 and 2013.

\subsection{Final Exam Performance}

The scores on the final exam deserve closer examination. The tests used each semester were identical except for rewording part of Problem 7 in an attempt to eliminate confusion that some students experienced. Figure 2 presents a box plot of the scores on each problem of the test each year. Scores on individual problems are scaled relative to the points for the problem. A score of 8 on a 10 point problem appears as a 0.75 in Figure 2.

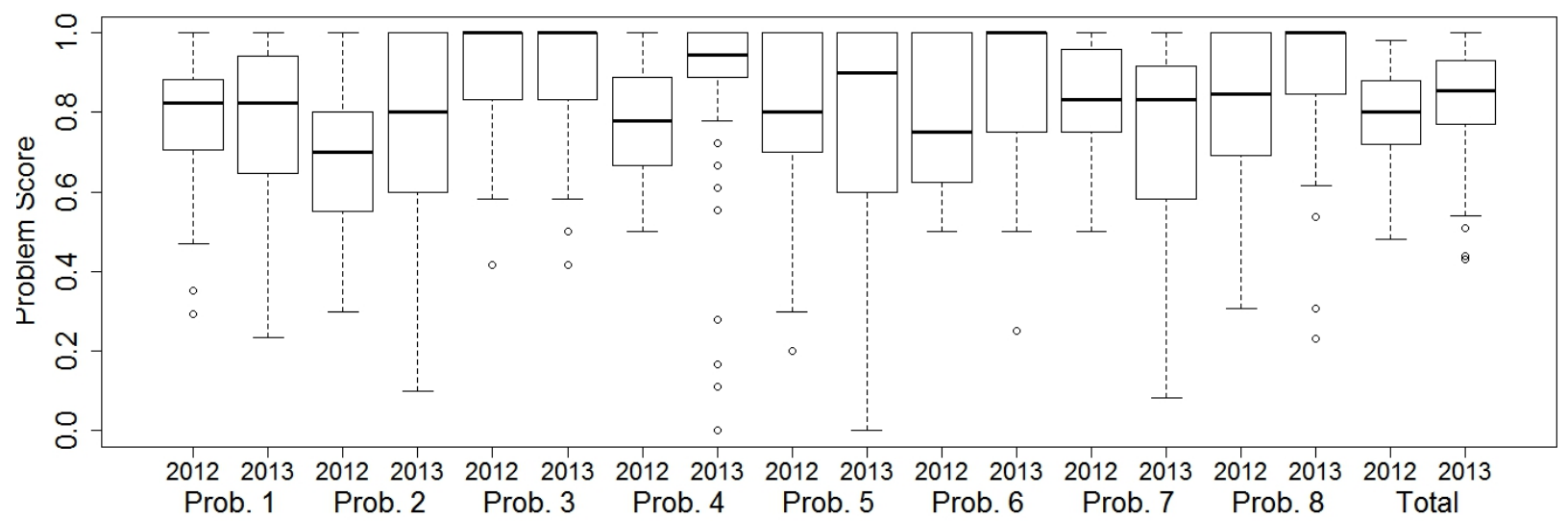

Figure 2. Distribution of Scores on Final Exam Questions

In general, three things are clear from the figure. First, the distributions of scores are not symmetric. This is not unexpected because there is a clear maximum score of 1.0 for each problem. Second, there was generally more variability the second semester. This will be discussed later. Finally, on every problem, the median score in 2013 was higher than the median score in 2012. Table 3 provides more insight. The average scores for Problems 3, 5, and 7 were higher in 2012 than in 2013. The scores on Problem 3 and 5 were virtually the same both 
years, suggesting that the difference in Problem 7 may have been due to rewording the problem. Because the data is severely asymmetric the means cannot be compared with t-tests, but differences in the median results were checked using the Mann-Whitney $U$ test through the Wilcoxon.test procedure in $\mathrm{R}^{7}$. Significant differences were found for 4 individual problems and the test as a whole.

Table 3. Perfomance on Final Exam Questions

\begin{tabular}{|c|c|c|c|c|c|c|}
\hline \multirow[b]{2}{*}{ Problem } & \multirow[b]{2}{*}{ Topics Covered } & \multicolumn{2}{|c|}{ Average Score } & \multicolumn{2}{|c|}{ Median Score } & \multirow{2}{*}{$\begin{array}{c}\text { Wilcoxon } \\
\text { rank sum test } \\
\text { p-value }\end{array}$} \\
\hline & & 2012 & 2013 & 2012 & 2013 & \\
\hline 1 & $\begin{array}{l}\text { Probabilty \& } \\
\text { Hypothesis Tests }\end{array}$ & 0.774 & 0.776 & 0.824 & 0.824 & 0.459 \\
\hline 2 & Discrete Distributions & 0.664 & 0.764 & 0.700 & 0.800 & $0.005 *$ \\
\hline 3 & Probability Rules & 0.910 & 0.910 & 1.000 & 1.000 & 0.874 \\
\hline 4 & $\begin{array}{l}\text { Normal Distribution/ } \\
\text { Central Limit Theorem }\end{array}$ & 0.789 & 0.879 & 0.778 & 0.944 & 1.09E-05* \\
\hline 5 & $\begin{array}{l}\text { Two Sample } \\
\text { Hypothesis Tests }\end{array}$ & 0.779 & 0.771 & 0.800 & 0.900 & 0.899 \\
\hline 6 & Confidence Intervals & 0.772 & 0.891 & 0.750 & 1.000 & $1.39 \mathrm{E}-04 *$ \\
\hline 7 & $\begin{array}{l}\text { One Sample } \\
\text { Hypothesis Tests \& } \\
\text { Type II Error }\end{array}$ & 0.823 & 0.762 & 0.833 & 0.833 & 0.2796 \\
\hline 8 & $\begin{array}{l}\text { Continuous } \\
\text { Distributions }\end{array}$ & 0.809 & 0.905 & 0.846 & 1.000 & 8.00E-03* \\
\hline Total & & 0.793 & 0.833 & 0.800 & 0.855 & $0.024 *$ \\
\hline
\end{tabular}

* Significant at $\alpha=0.05$

The increased variability in the scores of students in 2013 may reflect an inherent aspect of flipped classes. In any class there are some students who often miss class, and who do little work outside of class. These students should expect to do poorly because they have done nothing to learn the material. There are other students who may miss classes, but cram before a test and perform reasonably well. These students might succeed in a flipped class because they can watch the video lectues at the last minute, but they may be able to learn the material by reviewing homework and test solutions, too. Finally, there are students who attend class, but who don't work very hard outside of class. Those students are likely to do poorly in a flipped environment. In a traditional class, a student will learn something by attending lecture. In the flipped class, though, students who only attend lecture will never see the lectures. Then during class they will be ill-prepared to participate in the in-class activities. Consequently, they may be more likely to do poorly on the exams. These hypotheses could be evaluated more closely if records were available that showed how often students accessed the lecture videos. Correlations between in-class scores, lecture viewing and test scores could then be analyzed. Because the 
videos used in this class were not stored on Blackboard the necessary access records are not available.

\section{Student Reaction}

As was expected after the Fall 2012 trial run, student reaction to the flipped class approach was mixed. End-of-semester course evaluations were completed by 55 students. With respect to the general idea of flipping the class, only two students suggested that the course should be improved by going back to a traditional lecture format. Seven students explicitly commented that they liked the flipped method in ISYE 330. Two other students were more equivocal with one student saying, "I don't know whether I like the video/problems in class system”, and another saying, "I like the idea for the structure (reversed) of this class, but I'm not sure this class is best suited for it."

Where students had a positive response to the flipped environment, it was largely because of the in-class exercises. Many students said that the videos "detracted" from their learning. Four comments noted that the videos were "boring", 8 said they were too long, and 5 students made general comments indicating they didn't like the videos without specifying why. In the portion of the survey that asked how the course could be improved, 9 students suggested improving the videos. Because of the way that course comments are reported it is not possible to determine how many students made the similar comments in the "detracted" and "improvement" portions of the survey.

When identifying which parts of the class contributed most to their learning, most students mentioned one or two things such as the in-class exercises, or online problem solutions. The online videos were cited by 7 students, and 20 students explicitly cited the in-class exercises. Others mentioned the pre-exam review sessions, or the sample problem videos, or access to a library of previous exams. Perhaps one student summarized the intent and effectiveness of the course design with the comment:

"Dr. Olson provided a variety of ways to learn the material. Each student learns differently so this was a big help. We knew exactly how to study for each test. He provided us with extra sample problems with detailed explanations, previous tests along with solutions and video lectures which we were able to watch at our own pace and rewatch if we wanted to."

\section{Discussion}

Although there is no incontrovertible evidence that flipping ISYE 330 uiniformly improved student performance, there is evidence that it may have helped the students who were willing to work, and that students who did not work outside of class had difficulty. Still, this was the first time the class was flipped and in the process, many things were learned that should make it even more effective next time. The comments below reflect the author's observations based on his experience flipping ISYE 330 and may not conform to the experiences of others who have flipped their classes. 


\subsection{Positive results from flipping ISYE 330}

- It was very easy to stay on track and ensure that all the material was covered. In fact, 6-8 fewer days were needed to cover the material than in the traditional format. Part of this time savings came because the entire class didn't need to listen to answers to questions that only one or two people were struggling with. Instead, they continued to work.

- The additional time can be used to do new activities.

With several extra class periods available, the class can be revised to make it more valuable to students. This could be done by adding more topics that industrial engineers or other majors might find useful (e.g. nonparametric statistics), or the use of statistical software. The current topics could also be explored more deeply, for example, by introducing cases that are discussed in class. It could also be used to address general topics in probability and statistics raised by the Statistics Concept Inventory ${ }^{8}$. These kinds of questions will help students engage in the material in new ways and will lead to deeper learning. These activities may be particularly beneficial for the non-IEs in the class who often struggle to see the relevance of statistics to their disciplines.

- Course materials are available for students to use at their convenience. Many students find it very beneficial to be able to review a lecture several times. In some cases, students might review portions of a video several times before class. Other students might use the videos to refresh difficult ideas when preparing for a test.

- In-class sessions allow the instructor to more accurately gauge student learning. In a traditional lecture, even with active learning elements, the instructor is in control. Having students work on assignment in-class increases student/teacher interaction and it is easier to understand which concepts students struggle with, and also which topics they mastering easily. The time devoted to these topics can be changed as needed. It is also possible to identify individual students who are struggling and work more closely with them.

\subsection{Difficulties Encountered}

- Video lectures do not provide real time feedback on student learning to the instructor. In a traditional lecture format Think-Pair-Share and short problem solving activities provide meaningful feedback on where students are having problems and any misunderstanding can be corrected. When lectures are watched remotely, students might retain misconceptions longer. To some extent, this can be ameliorated by continuing to include question/answer and short problem activities in the videos.

- Videos are less personal and discourage enlightening digression.

In a video format, with no personal connections, stories are hard to motivate and jokes don't work well. Yet these are the things that often break up the monotony in a class and build a connection between the students and instructor. One of the benefits of having real-world experiences is that they can be drawn on as needed to make a specific point in response to a specific question. It is hard to do this in video.

- Some students will not take responsibility for their own learning.

Even though the videos for any day took less than one hour to view, there were always some people who hadn't watched them, and there were a few people who seldom watched them. Because lectures aren’t fully repeated during class, these students may fall behind. The best resolution for this problem is to make certain that the students 
understand that they are responsible for preparing for lectures. This may be more easily ensured if there are lecture quizzes that must be completed before class or at the beginning of class.

- Preparing videos takes a great deal of time

ISYE 330 required the recording of 63 lecture videos. Even though the PowerPoint lectures already existed making the videos took a long time. It is advisable to begin by creating a few software demonstration videos or other short lessons to learn the software and develop a workflow for preparing videos. Even then, the time required to record a video may be similar to the time needed to create the PowerPoint lecture.

\subsection{Suggestions for new adopters - or people revising their materials}

- Include one or two Think-Pair-Share questions during the mini-lecture.

This will provide an opportunity for class-wide interaction. Because the students have had a chance to think about the lecture, these questions can be conceptual, or related to applying the material. The questions could also be posed at the end of the video material for discussion at the beginning of class.

- Keep the videos short.

Don't elaborate unnecessarily on the video. Get to the point, and move on or you will lose viewer interest. It is better to break a lecture into several short chapters than to keep it intact. Student will be able to watch a short video when they have free time, and they will be able find specific topics more easily

- Don't put lecture or page numbers on the videos

It is likely that you will revise a class by adding new material, or rearranging topics. You might also use material from one class as a refresher in another. Having lecture and page numbers in the videos will likely confuse students if the video numbers aren't in sync with the rest of the class. Leaving that information off the video makes means that you can simply rename files to reorder lectures.

- Treat in-class assignments formally like homework teams. Assign the team members rotating roles are recorders, organizers, checkers and proofers. That will keep everyone engaged and ensure that one person isn't doing all of the work.

- Find a room with space for collaboration.

It will be difficult for students to work together in a room with fixed seating. It is also difficult for the instructor to move between groups. Request a classroom with movable desks. Even better is to use rooms with tables that can accommodate 3-4 people.

\section{Bibliography}

1. Montgomery, D. C., and G. C. Runger, Applied Statistics and Probability for Engineers, $5^{\text {th }}$ ed., Wiley, 2010.

2. Bishop, J. L., and M. A. Vergler, "The Flipped Classroom: A Survey of the Research," in $120^{\text {th }}$ ASEE Annual Conference, Atlanta, GA, 2013.

3. Kellog, S., "Developing Online Materials to Facilitate an Inverted Classroom Approach", $39^{\text {th }}$ ASEE/IEEE Frontiers in Education Conference, San Antonio, TX, 2009.

4. Toto, R. and H. Nguyen, "Flipping the Work Design in an Industrial Engineering Course", $39^{\text {th }}$ ASEE/IEEE Frontiers in Education Conference, San Antonio, TX, 2009.

5. R. M. Felder, R. Brent, and M. Prince, National Effective Teaching Institute (NETI), Charlotte, NC, June 2012.

6. Kahn Academy website: https://www.khanacademy.org/ accessed 12/20/13. 
7. R Core Team R: A language and environment for statistical computing. $R$ Foundation for Statistical Computing. (2012). at http://www.R-project.org/ accessed 12/20/13.

8. Statistics Concept Inventory website, https://engineering.purdue.edu/SCI accessed 12/20/13.

9. SmoothDraw website, http://www.smoothdraw.com accessed 12/20/13.

10. Classroom Presenter website, http://classroompresenter.cs.washington.edu/ accessed 12/20/13.

\section{Appendix: Preparation of online materials}

The flipped implementation of ISYE 330 includes video lectures, and videos of solutions to textbook problems. Both types of material were recorded on a PC running Window 7 using a Blue Snowflake microphone, and Wacom Bamboo Tablet to make annotations. Adobe Captivate was used in full motion mode to capture and edit the video. Files were saved in the mp4 format to allow playback in Windows or iOS. In additions, SmoothDraw $4^{9}$ was used to create the problem solutions and Classroom Presenter ${ }^{10}$ was used to prepare the lecture videos. The recording procedures have evolved since 2010 through trial and error. The procedures used most recently are described below.

\section{A.1 Recording lecture video}

Videos of the lectures were recorded to emulate the way the PowerPoint is typically used by the instructor in the classroom. When preparing PowerPoint lectures, the instructor makes extensive use of Classroom Presenter. This program offers two important features. First, when creating the slides in PowerPoint, some content can be tagged as instructor notes. When Classroom Presenter is used to make the presentation, the tagged notes appear on the Classroom Presenter screen that can be read by the instructor, but they are not projected to the audience. These notes can be elaborations that you want to be certain to mention, but they can also include solutions to problems. The second feature is that the presentation is delivered in dual screen mode. The PowerPoint content and instructor notes are delivered to the primary screen which includes tools for annotating the slides. The secondary screen is used to display the lecture without any of the instructor notes, but with any annotations added during the lecture. This makes it easy to work out a solution in class. First, create the solution in PowerPoint, then tag the solution as an instructor note. Since this will appear on your screen during lecture, the solution can be projected by copying the solution with a tablet pen on the Classroom Presenter screen.

The lectures recorded for ISYE 330 were created by using a dual screen computer with Adobe Captivate recording the dual monitor while annotations were made in the primary display using the tablet. Videos were recorded at a resolution of 1280x1024. The lectures were delivered as if they were being presented to a class. Where a problem would be worked out by the instructor in class, the tablet pen was used to solve the problem. Where a question would normally be posed, students were given 5-15 seconds to think about an answer. Where students would work on a problem in class, students were asked to pause the video while they worked on the problem, then the solution was given. Initially, entire lectures were presented as one video, but in response to student comments, most handouts were broken into 3-4 videos taking 6-12 minutes. Consequently, topics that might normally take 50-90 minutes to deliver in lecture result in only 25-45 minutes of video depending on the degree of student interaction during class. 


\section{A.2 Recording textbook problem solutions}

Rather than use PowerPoint, the solutions to textbook problems were made by using SmoothDraw 4 to write out solutions. SmoothDraw is designed as a drawing program but its palette of writing tools makes it versatile and well-suited for writing solutions. To write the solutions, a 660x780 canvas was created. The problem statement was inserted at the top of the canvas, and then Captivate was used to record the solution. Initially, the problem statements were scanned from the text, and cut/paste into SmoothDraw, but it is also possible to grab a screen image from an online version of the text.

\section{A.3 Other video considerations}

Recording video is a very time-consuming process. Recording all of the lectures for a handout could take 1-4 hours depending on the complexity of the lecture, and the instructor's tolerance for gaffes. Besides learning the software, you must learn to write on a tablet resting on a desktop, while looking at a monitor. Recording would be much faster with a script, but then writing the script would take time and would need to be coordinated with the annotations. It is quite difficult to read a script while writing out a problem because you need to watch one part of the screen to read the text and another to make certain you are writing in the correct place. Recording problem solutions was much faster than recording lectures; they could usually be recorded in 10-20 minutes.

All Captivate recordings need to be converted into mp4 format. This could take as long as an hour long for lectures with many annotations, but this conversion can take place in the background.

After the videos are recorded, they need to be delivered to the students. USD has a computer dedicated to storing video content for online delivery, so all files were moved to that computer. Blackboard was used to organize the content providing links to the videos and to pdf solutions to other problems. 